\title{
Preparation of Narrow-Molecular-Weight-Distribution Poly(tetrahydrofuran)
}

\author{
Teruo Fujimoto, Masaru Kawahashi, Mitsuru Nagasawa, \\ and Akira TAKAHASH* \\ Department of Synthetic Chemistry, Nagoya University, Nagoya 464, Japan. \\ *Chemistry Department of Industry and Resources, Mie University, \\ Tsu, Mie 514, Japan.
}

(Received March 9, 1978)

\begin{abstract}
The preparation method for the monodisperse crystallizable polymer, poly(tetrahydrofuran), was studied over a wide range of molecular weights. Bulk polymerization of tetrahydrofuran (THF) was carried out by introducing THF monomer into a completely reacted trifluoroboron- $\mathrm{THF}$ - ethylene oxide catalyst-promoter system, with vigorous stirring. This initiation technique had no induction period. Both molecular weights and conversion increased linearly with reaction time. The molecular weight distribution evaluated by the sedimentation method as well as light scattering and osmometry was very sharp and $\bar{M}_{w} / \bar{M}_{n}$ was less than 1.01 even at the $\bar{M}_{w}=10^{6}$. When the polymerization is stopped at a low conversion $(8 \%)$, which is far from the equilibrium, the in-chain transfer reaction is negligible.
\end{abstract}

KEY WORDS Poly(tetrahydrofuran) / Narrow Molecular Weight Distribution / Trifluoroboron-THF-Ethylene Oxide / CatalystPromoter / Impurity / Chain Transfer /

Much progress has been made in the study of the physical properties of amorphous polymers since the preparation of monodisperse polystyrene by Szwarc. ${ }^{1}$ It seems unnecessary to stress the importance of monodisperse crystallizable polymers in the study of polymer physics. A few monodisperse crystallizable polymers [poly(tetrahydrofuran), poly(ethylene oxide) have] been prepared.

The purpose of this work is to study the preparation method for the monodisperse crystallizable polymer, poly(tetrahydrofuran) (PTHF), over a wide range of molecular weights. It was pointed out $^{2,3}$ that tetrahydrofuran (THF) can be polymerized on a living mechanism, by certain ring opening cationic initiators, and several papers ${ }^{4-10}$ have been published on the preparation of PTHF of narrow molecular weight distributions. However, these molecular weight distributions are not narrow enough and the molecular weight ranges covered are not wide enough. It is essential in the study of physical properties to have samples not only with sharp molecular weight distributions but also a wide molecular weight range.

There are various cationic initiators presented in previous works: trifluoroboron $\left(\mathrm{BF}_{3}\right)$-ethylene oxide (EO) catalyst, ${ }^{4,5}$ triethyloxonium hexachloroantimonate, ${ }^{6}$ trifluoromethanesulfonic anhydride, ${ }^{7}$ and $p$-chlorophenyldiazonium hexafluorophosphate. $^{8}$ If triethyloxonium hexachloroantimonate, trifluoromethanesulfonic anhydride and $p$ chlorophenyldiazonium hexafluorophosphate are selected as initiators, the active chain ends may cause chain transfer reactions and, moreover, the products produced when they react with impurities (e.g. $\mathrm{SbCl}_{5}, \mathrm{CF}_{3} \mathrm{SO}_{3} \mathrm{H}, \mathrm{PF}_{5}$ ) may be able to undergo slow initiation by dimerization. ${ }^{2}$ Those unfavor able reactions may broaden the molecular weight distributions of the products and, in practice, the polydispersity ratio $\left(\bar{M}_{w} / \bar{M}_{n}\right)$ reported in literature is $1.04-1.08$. It was reported by Croucher and Wetton ${ }^{8}$ that the $\mathrm{PF}_{6}{ }^{-}$gegenion of the initiator should be kept above the ceiling temperature. This is probably because of the production of $\mathrm{PF}_{5}{ }^{11}$ Such unfavorable side reactions do not occur in the polymerization of THF with triethyloxonium tetrafluoroborate and $\mathrm{BF}_{3}-\mathrm{THF}$ catalyst. However, the ratio $\bar{M}_{w} / \bar{M}_{n}$ of PTHF was found to be almost 2 by Makletsova, et al. ${ }^{12}$ Taking this literature into account, we selected a catalyst-promoter system; that is, the $\mathrm{BF}_{3}-\mathrm{THF}$ complex as a catalyst and 
ethylene oxide as a promoter.

With this initiator, Johnston ${ }^{4}$ obtained a very low molecular weight PTHF, the molecular weight distribution being somewhat broader than the Poisson distribution. Ofstead ${ }^{5}$ obtained also PTHF with $\bar{M}_{w} / \bar{M}_{n}=1.04$ for low molecular weight samples; however, the high molecular weight samples had rather broad molecular weight distributions. To obtain very high molecular weight samples with narrow molecular weight distribution, it is necessary to use very low catalyst concentration since the molecular weights are inversely proportional to catalyst concentration. Moreover the reaction probability between catalyst and promoter in the initiation stage should be very low when using the mixing procedure of Johnston and also of Ofstead. Therefore, to avoid a possible delayed initiation stage compared with propagation, which may lead to broadening of molecular weight distribution, we used a different order of mixing of catalyst-promoter and monomer to that employed by Johnston ${ }^{4}$ and Ofstead. ${ }^{5}$ In this catalyst system, it is necessary to add a promoter such as EO, propylene oxide (PO) and as well as epichlorohydrine (ECH). Saegusa, et al. ${ }^{10}$ reported that EO and ECH are more effective than $\mathrm{PO}$ as promoter. However, Booth, et al. ${ }^{13,14}$ reported that the melting temperatures of polyether such as poly(ethylene oxide) are much affected by the character and structure of end group, especially by chlorine atom. Since crystallization and melting of low molecular weight PTHF with $\mathrm{OH}$ end group have been reported by several authors, ${ }^{15-17}$ we prefered here to use EO as a protomer in the study of the molecular weight dependence of the crystallization of PTHF.

\section{PREPARATION}

\section{Purification of THF and EO}

The apparatus and technique for the purification of THF and EO were similar to those described previously. ${ }^{18}$ The vacuum line was pumped to $10^{-6} \mathrm{mmHg}$ pressure. THF (Katayama Chemical Co.) was fractionally distilled by a conventional procedure and then refluxed over sodium metal for several hours. This procedure was repeated twice and THF was distilled into a flask containing a few pieces of sodium and anthracene. The liquid was repeatedly degased at $-78^{\circ} \mathrm{C}$ and re- fluxed until a permanent blue color remained. EO gas was collected as liquid in a flask by cooling it with dry-ice-acetone. The EO liquid was dried with $\mathrm{CaH}_{2}$ for hrs. in vacuo, and then fractionally distilled twice in vacuo.

\section{Preparation of the Initiator, $\mathrm{BF}_{3}-\mathrm{THF}$ Complex}

$\mathrm{BF}_{3}$-THF complex was prepared by a reaction of $\mathrm{BF}_{3}$ gas with liquid THF. A flask containing purified THF was filled with dry $\mathrm{N}_{2}$ gas, and then $\mathrm{BF}_{3}$ gas flowed into the liquid THF through a capillary. After reacting $\mathrm{BF}_{3}$ with $\mathrm{THF}$ for about $1 \mathrm{~h}$ the inlet tube for the $\mathrm{BF}_{3}$ gas was sealed off. The complex formed was solidified by cooling it to $-78^{\circ} \mathrm{C}$ and the whole apparatus was evacuated. The complex was fractionally distilled twice in vacuo. The fraction in the range of $58-60^{\circ} \mathrm{C}$ under $10^{-6} \mathrm{mmHg}$ was collected.

\section{Polymerization}

The bulk polymerization of THF was carried out in the apparatus shown in Figure 1, in which $\mathrm{F}$ is the reaction vessel, $A, B, C$, and $D$ flasks serving as sampling flasks for the reaction mixture. Flask $\mathrm{T}_{1}$ contains monomer THF, ampules $\mathrm{T}_{2}, \mathrm{I}$ and $\mathrm{P}$ contain THF used for washing the apparatus, $\mathrm{BF}_{3}$ THF complex and the promoter EO; respectively, and ampule $\mathrm{E}$ was used to collect THF after washing the apparatus. The polymerization was performed at $10^{-6} \mathrm{mmHg}$ in the following manner. (1) The breakable seal of the ampule I was broken and the $\mathrm{BF}_{3}$-THF complex was introduced into flask F. (2) The breakable seal of $T_{2}$ was opened and ampule I was washed with THF. This THF

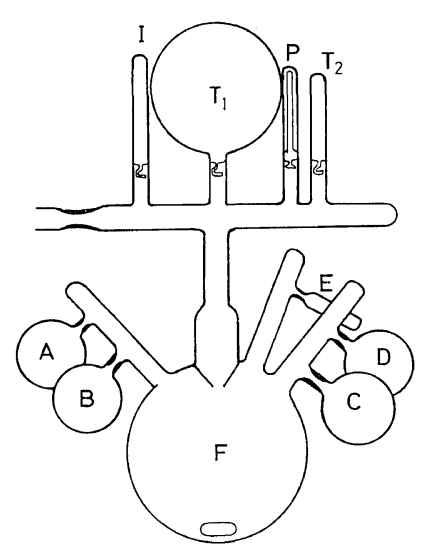

Figure 1. Apparatus for polymerization: symbols are shown in the text. 
was put into flask E and sealed off. (3) The breakable seal of the promoter ampule $P$, made by a calibrated capillary on inner diameter $\phi=$ $0.2 \mathrm{~mm}$, was opened and EO was transferred into flask $\mathrm{F}$ with vigorous stirring to react with $\mathrm{BF}_{3}$ THF complex. To ensure the complete transfer of $\mathrm{EO}$ into the reaction flask $\mathrm{F}$, flask $\mathrm{F}$ was cooled by dry-ice-acetone and the apparatus was warmed for $30 \mathrm{~min}$. By doing so, the catalyst-promoter reaction between $\mathrm{EO}$ and $\mathrm{BF}_{3}-\mathrm{THF}$ complex was completed. The completion of the reaction between $\mathrm{EO}$ and $\mathrm{BF}_{3}-\mathrm{THF}$ complex was confirmed by observing that no EO condensed on the ampule $\mathbf{P}$ wall when ampule $\mathrm{P}$ was cooled by dry ice-acetone. Then, the breakable seal of $\mathrm{T}_{2}$ was broken, keeping the temperature of flask $\mathrm{F}$ at $0^{\circ} \mathrm{C}$ and stirring the flask $\mathrm{F}$ with a magnetic stirrer. The bulk polymerization of THF started immediately. At appropriate times, the reaction mixture was transferred into flasks A, B, C, and D which were sealed off at a scheduled time. The PTHF formed at different reaction times was precipitated as solid cakes, by pouring the reaction mixtures into dilute $\mathrm{NaOH}$ aqueous solutions. The precipitated polymers were purified by repeating the dissolution and precipitation with THF and $\mathrm{H}_{2} \mathrm{O}$. After vacuum drying, the polymer was again dissolved in benzene and freeze-dried.

\section{MEASUREMENTS}

\section{Molecular Weight Determination}

The weight-average molecular weights were determined from light scattering measurements, using modified Shimazu light scattering photometer described previously. ${ }^{19}$ The calibration of the instrument was carried out by using both

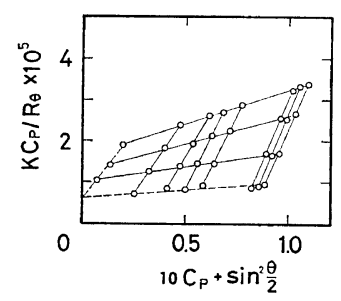

Figure 2. An example of the Zimm plot of sample $\mathrm{T}-3-5$ in ethyl acetate solution at $30^{\circ} \mathrm{C}: C_{\mathrm{p}}$, polymer concentration in $\mathrm{g} / \mathrm{d} l ; R_{\theta}$, the Rayleigh scattering ratio at the angle $\theta ; K$, the optional constant. benzene and NBS standard polystyrenes. Ethyl acetate was employed as the solvent, and measurements were carried out at $30^{\circ} \mathrm{C}$ with $436 \mathrm{~nm}$ by using a differential refractometer of the Debye type. All solutions were cleaned by filtration through membrane filters Dularon-NRWP 0470025 ca. NR. A typical Zimm plot obtained is shown in Figure 2.

The number-average molecular weights were determined by using a Mechrolab high speed membrane osmometer, Model 502, fitted with a membrane $0-8$. Toluene was used as solvent and the measurements were carried out at $25^{\circ} \mathrm{C}$. Intrinsic viscosities of the samples in benzene or in toluene were measured with a modified Ubbelohde viscometer. The viscosity-average molecular weights were calculated according to the following equations.

$$
\begin{array}{lll}
{[\eta]=1.31 \times 10^{-3} \bar{M}_{n}^{0.60}} & \left(\text { Benzene, } 30^{\circ} \mathrm{C}\right) & (1)^{20} \\
{[\eta]=2.36 \times 10^{-4} \bar{M}_{n}^{0.77}} & \left(\text { Toluene, } 30^{\circ} \mathrm{C}\right) & (2)^{5}
\end{array}
$$

The values of $\bar{M}_{v}$ calculated from both equations agreed each other and also agreed with the values of $\bar{M}_{n}$ determined directly.

\section{Molecular Weight Distribution Determination from Sedimentation Velocity}

The molecular weight distributions of selected samples were measured by the sedimentation velocity method. A Spinco Model E ultracentrifuge was used, and the sedimentation experiments were performed at $59760 \mathrm{rpm}$. using a mixed $\theta$ solvent, that is, a mixture of hexane $(77.3 \mathrm{wt} \%)$ and ethylacetate $(22.7 \mathrm{wt} \%)$ at $30.4^{\circ} \mathrm{C}^{20}$

Care was taken that the sample solution should not be cooled below the $\theta$ temperature before being placed in a centrifuge cell. Kurata, Utiyama, and $\mathrm{Kamada}^{20}$ reported the concentration dependence of the sedimentation velocity of PTHF in the mixed solvent, at a slightly higher operation temperature, and observed a small concentration dependence. However, on employing such dilute solutions as $0.1 \mathrm{~g} / 100 \mathrm{ml}$, we found that sedimentation velocity was independent of the polymer concentration. Thus, the molecular weight distribution was calculated from sedimentation patterns at one concentration between 0.1 and $0.15 \mathrm{~g} / 100 \mathrm{ml}$. A correction for diffusion was obtained by extrapolating the results obtained at different times to an infinite time; but no correction was made for the 
pressure effect. The actual calculation procedure of the molecular weight distribution from sedimentation patterns followed the method of Homma, Kawahara, Fujita and Ueda. ${ }^{21}$

\section{RESULT AND DISCUSSION}

The viscosity average molecular weights of the polymers at different polymerization times in an experiment are listed in Table I. The conversion vs. reaction time is also plotted in Figure 3. It is

Table I. Bulk polymerization of tetrahydrofuran (THF) of $\mathrm{T}-3$ series

\begin{tabular}{cccc}
\hline $\begin{array}{c}\text { Sample } \\
\text { No. }\end{array}$ & $\begin{array}{c}\text { Polymerization } \\
\text { time, min }\end{array}$ & $\begin{array}{c}\text { Conversion, } \\
\%\end{array}$ & $\begin{array}{c}\bar{M}_{v} \\
\times 10^{-4}\end{array}$ \\
\hline $\mathrm{T}-3-1$ & 65 & 2.05 & 3.9 \\
2 & 120 & 3.40 & 7.7 \\
3 & 178 & 4.42 & 9.3 \\
4 & 248 & 5.41 & 10.5 \\
5 & 363 & 8.68 & 18.1 \\
\hline
\end{tabular}

a THF, $12.3 \mathrm{~mol} / l ; \mathrm{BF}_{3}-\mathrm{THF}, 0.051 \mathrm{~mol} / l ; \mathrm{EO}$, $0.0016 \mathrm{~mol} / l$.

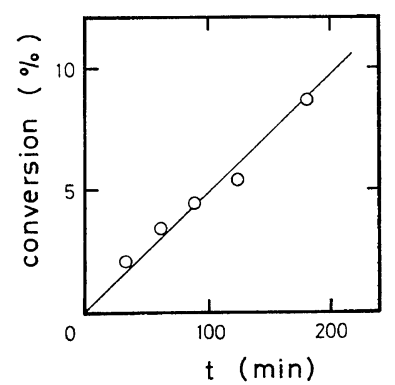

Figure 3. Plot of conversion vs. reaction time for $\mathrm{T}-3$ series in Table $\mathrm{I}$.

evident from the figure that no induction period is observed in the present experiments. Ofstead ${ }^{5}$ observed an induction period of several minutes, though he used the similar catalyst-promoter system. This difference may result from the difference in the manner of addition of the catalyst, the promoter, and the monomer into the reaction flask $\mathrm{F}$. In the experiment of Ofstead, the $\mathrm{BF}_{3}$ THF complex was injected over a period of $10 \mathrm{~s}$ into the THF monomer which already contained EO, whereas we first completely reacted the $\mathrm{BF}_{3}-\mathrm{THF}$ complex with EO, and then intro-

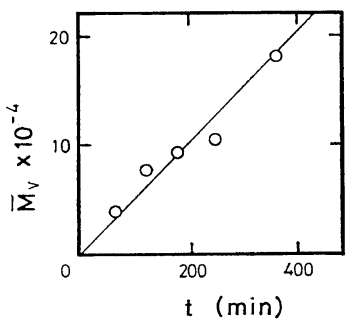

Figure 4. Plot of molecular weight $v s$. reaction time for $\mathrm{T}-3$ series in Table $\mathrm{I}$.

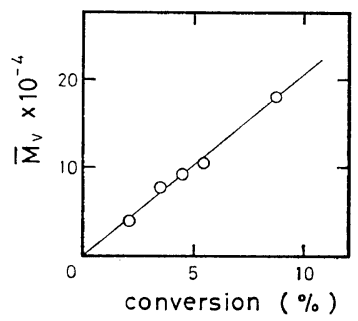

Figure 5. Plot of molecular weight vs. reaction time for $\mathrm{T}-3$ series in Table I.

duced THF monomer with vigorous stirring.

Figure 4 shows the relationship between the molecular weight and the reaction time in the experiment of Table I. The plot is linear and passes through the origin. Thus, the relationship between the conversion and molecular weight is also linear, as is shown in Figure 5, showing the living polymerization of THF. Although we could not obtain enough conversion data in other experiments, the molecular weight increased almost linearly with time in the experiments, as shown in Table II.

If there is no induction period and the polymerization proceeds under an equilibrium condition, the polymerization rate is expressed $a^{22}$

$$
-\mathrm{d}[\mathrm{M}] / \mathrm{d} t=k_{\mathrm{p}}\left[\mathrm{M}^{*}\right]\left\{[\mathrm{M}]-[\mathrm{M}]_{\theta}\right\}
$$

where $\left[\mathrm{M}^{*}\right],[\mathrm{M}]$ and $[\mathrm{M}]_{e}$ are the active species, instantaneous and equilibrium monomer concentrations, respectively. The concentration of active species can be calculated from the amounts of polymer obtained and their molecular weights. At a reaction temperature of $0^{\circ} \mathrm{C}$, the equilibrium monomer concentration has already been estimated from the data of Smith and Dreyfuss, et al. ${ }^{2}{ }_{\varepsilon}$ to be $1.70 \mathrm{~mol} / l$. The values of $\ln \left\{[\mathrm{M}]_{0}-[\mathrm{M}]_{\mathrm{e}} /\right.$ 
Preparation of Narrow-Molecular-Weight-Distribution Polytetrahydrofuran

Table II. Bulk polymerization of THF of other series

\begin{tabular}{|c|c|c|c|c|c|}
\hline $\begin{array}{l}\text { Sample } \\
\text { No. }\end{array}$ & $\underset{\mathrm{mol} / \mathrm{l}}{\mathrm{Monomer}}$ & $\begin{array}{l}\mathrm{BF}_{3}-\mathrm{THF} \\
\times 10^{2}, \mathrm{~mol} / l\end{array}$ & $\begin{array}{c}\mathrm{EO} \\
\times 10^{3}, \mathrm{~mol} / \mathrm{l}\end{array}$ & $\begin{array}{l}\text { Polymerization } \\
\text { time, min }\end{array}$ & $\begin{array}{l}\bar{M}_{v} \\
\times 10^{-4}\end{array}$ \\
\hline $\begin{array}{r}\mathrm{T}-1-1 \\
2 \\
3\end{array}$ & 12.3 & \} 6.8 & \} 6.5 & $\begin{array}{r}35 \\
65 \\
120\end{array}$ & $\begin{array}{l}1.3 \\
2.3 \\
4.2\end{array}$ \\
\hline $\begin{array}{r}T-2-1 \\
2 \\
3\end{array}$ & 12.3 & 3.4 & \} 0.95 & $\begin{array}{r}375 \\
721 \\
1115\end{array}$ & $\begin{array}{l}27.8 \\
49.5 \\
87.0\end{array}$ \\
\hline $\begin{array}{r}T-4-1 \\
2\end{array}$ & \} 12.3 & 38.5 & 326 & $\begin{array}{l}27 \\
40\end{array}$ & $\begin{array}{l}1.4 \\
6.5\end{array}$ \\
\hline $\begin{array}{r}T-5-1 \\
2 \\
3\end{array}$ & \} 12.3 & \} 2.1 & \} 0.23 & $\begin{array}{l}1333 \\
2723 \\
4288\end{array}$ & $\begin{array}{l}51.5 \\
80.0 \\
100\end{array}$ \\
\hline $\begin{array}{r}T-6-1 \\
2 \\
3\end{array}$ & 12.3 & \} 2.1 & \} 0.12 & $\begin{array}{r}2980 \\
7125 \\
11425\end{array}$ & $\begin{array}{l}140 \\
170 \\
180\end{array}$ \\
\hline
\end{tabular}

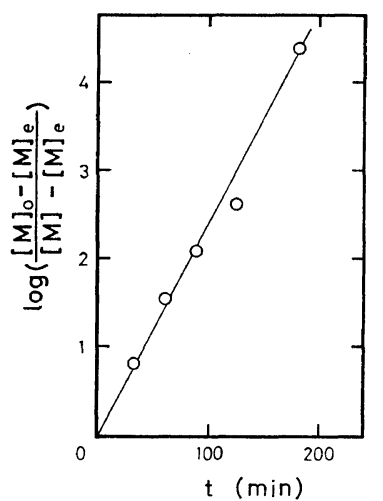

Figure 6. Plot of $\log \left\{\left([\mathrm{M}]_{0}-[\mathrm{M}]_{\mathrm{e}}\right) /\left([\mathrm{M}]-[\mathrm{M}]_{\mathrm{e}}\right)\right\}$ vs. reaction time. $[\mathrm{M}]_{0},[\mathrm{M}]$, and $[\mathrm{M}]_{\mathrm{e}}$ are initial, instantaneous, and equilibrium concentration of the monomer.

$[\mathrm{M}]-[\mathrm{M}]_{e}$ \} are calculated from the data in Table I with this value of $[\mathrm{M}]_{e}$ and plotted against reaction time, as shown in Figure 6. The propagation rate constant, $k_{\mathrm{p}}$, can be determined as $0.276 \mathrm{l} / \mathrm{mol} \mathrm{min}$. from the slope. This value is in good agreement with the value, $4.83 \times 10^{-3} l / \mathrm{mol} \mathrm{s}$, reported by Tobolsky, et al., ${ }^{22}$ but is twice as high as that reported by Croucher, et al. ${ }^{8}$ In the polymer prepared from the THF by using the $\mathrm{BF}_{3}-\mathrm{THF}$ complex and EO, it must be considered that there is at least one EO unit in each polymer chain. The number of EO units can be calculated from the amount of polymer obtained, EO charged, and their molecular weights. It was found that there are three to five EO units for each polymer chain in sample $\mathrm{T}-3$ or $\mathrm{T}-2$ series.

The weight average $\left(\bar{M}_{w}\right)$ and number average $\left(\bar{M}_{n}\right)$ molecular weights determined by light scattering and osmotic pressure measurements are listed in Table III, together with the ratio $\bar{M}_{w} / \bar{M}_{n}$. The molecular weight distributions of the polymers calculated from sedimentation experiments are shown in Figure 7 , and the values of $\overline{\boldsymbol{M}}_{w} / \bar{M}_{n}$

Table III. Molecular weight and molecular weight distribution

\begin{tabular}{ccccc}
\hline $\begin{array}{c}\text { Sample } \\
\text { No. }\end{array}$ & $\bar{M}_{n} \times 10^{-4}$ & $\bar{M}_{w} \times 10^{-4}$ & $\bar{M}_{w} / \bar{M}_{n}$ & $\begin{array}{c}\bar{M}_{w} / \bar{M}_{n}{ }^{a}, \\
\text { sed }\end{array}$ \\
\hline T-1-3 & 4.0 & 4.2 & $1.0_{5}$ & 1.07 \\
T-2-3 & & 83.3 & & $1.00_{1}$ \\
T-3-5 & 16.7 & 17.6 & $1.0_{5}$ & $1.00_{8}$ \\
T-5-1 & & 51.3 & & $1.00_{5}$ \\
\hline
\end{tabular}

a From sedimentation experiments.

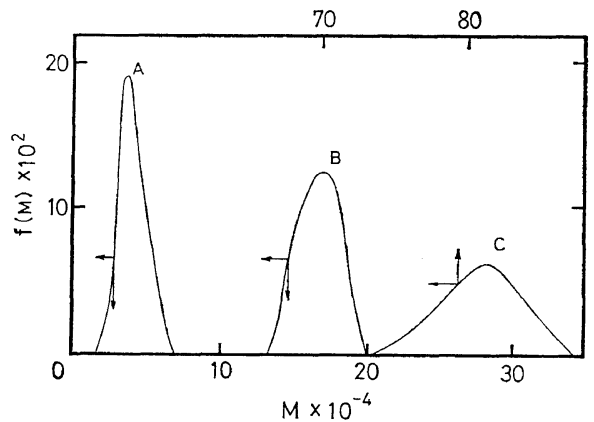

Figure 7. Molecular weight distribution: $A, T-1-3$; B, T-3-5; C, T-2-3. 


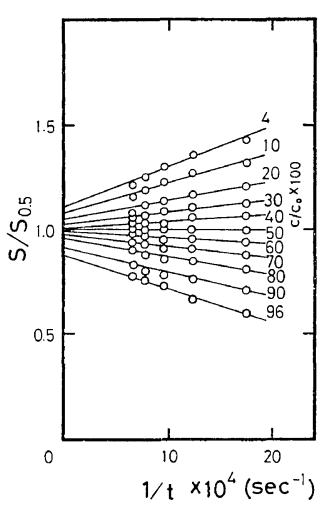

Figure 8. Sedimentation velocity of sample $\mathrm{T}-3-5$ at various concentrations in ethyl acetate and hexane mixed solvent at $30.4^{\circ} \mathrm{C}$.

calculated from the distribution curves are also listed in Table III. The ratio $\bar{M}_{w} / \bar{M}_{n}$ which is usually used to express the degree of molecular weight distribution is close to unity. The molecular weight distribution of PTHF obtained by this method may thus be concluded to compare sharply with those so far published. To show the reliability of such a sharp molecular weight distribution, the sedimentation constants of molecules at various concentration points in a sedimentation pattern are plotted against inverse time in Figure 8 in relation to the sedimentation constant at the half concentration point. The sample is T-3-5 in Table I. $S$ and $S_{0,5}$ are the sedimentation constants of the molecules which are at the positions of concentration $C$ and $0.5 C_{0}$ respectively, (where $C_{0}$ denotes the initial concentration). All straight lines at different $C / C_{0}$ converge in the vicinity of unity at $1 / t=0$, in agreement with previous results for poly $\alpha$-methylstyrene obtained by anionic polymerization. ${ }^{18}$

In the bulk polymerization of THF, slow initiation reactions, the equilibrium effect between the active chain end and monomer and also the possible chain transfer reactions may be the factors causing a broadening of the molecular weight distribution of PTHF. ${ }^{2,8}$ Since the induction period is not observed in this experiments and the number of active species should be proportional to the amount of $\mathrm{EO}$ and $\mathrm{BF}_{3}-\mathrm{THF}$ complex, the velocity of initiation with the present catalyst-promoter system may be much faster than that of propagation. The molecular weight distribution cannot be narrow if polymerization-depolymerization equilibrium is attained; but in these experiments, polymerization was stopped considerably before equilibrium was attained, at a conversion below $8 \%$. The second effect may by negligible. ${ }^{24}$ Although the level of impurities in our system is very low, it may be true that there are possible chain transfer reactions in the present polymerization system; that is, the reaction of in-chain oxygens of the polymer with growing species and the reaction of the growing chain-ends with counter ions. In particular, the latter chain transfer reaction may occur easily when the counter ion is $\mathrm{BF}_{4}^{-}$rather than $\mathrm{SbF}_{6}{ }^{-}$ and $\mathrm{PF}_{6}{ }^{-}$. However, it may be concluded from the present experimental results that these chain transfer reactions are negligible in the present polymerization system.

\section{REFERENCES}

1. M. Szwarc, "Carbanions Living Polymer and Electron Transfer Processes," Interscience Publishers, New York, N. Y., 1968.

2. P. Dreyfuss and M. P. Dreyfuss, Adv. Polym. Sci., 4, 528 (1967).

3. P. Dreyfuss and M. P. Dreyfuss, Adv. Chem. Ser., 91, 1 (1969).

4. P. R. Johnston, J. Appl. Polym. Sci., 9, 467 (1965).

5. E. A. Ofstead, Polym. Prepr., 6, 674 (1965).

6. J. Stejny, J. Macromol. Sci. Chem., A 7, 1435 (1973).

7. S. Smith and A. J. Hubin, J. Macromol. Sci. Chem., A 7, 1399 (1973).

8. T. G. Croucher and R. E. Wetton, Polymer, 17, 205 (1976).

9. T. Saegusa, H. Imai, and J. Furukawa, Makromol. Chem., 65, 60 (1963).

10. H. Imai, T. Saegusa, S. Matsumoto, T. Tadasa, and J. Furukawa, Makromol. Chem., 102, 222 (1967).

11. D. Smith, J. Chem. Soc., 864 (1964).

12. N. V. Makletsova, I. V. Epel'baum, B. A. Rozenberg, and E. B. Lyvdving, Vysokomol. Soedin. 7, 70 (1965).

13. L. Booth and J. M. Bruce, Muggy, Polymer, 13, 475 (1972).

14) P. C. Ashman and C. Booth, Polymer, 14, 300 (1973).

15. R. E. Wetton and G. Williams, Trans. Faraday Soc., 61, 2132 (1965).

16. M. Cesari, G. Perego, and A. Mazzei, Makromol. 
Preparation of Narrow-Molecular-Weight-Distribution Polytetrahydrofuran

Chem., 83, 196 (1965).

17. G. S. Trick and J. M. Ryan, J. Polym. Sci., Part C, 18, 93 (1967).

18. T. Fujimoto, N. Ozaki, and M. Nagasawa, $J$. Polym. Sci., Part A, 3, 2259 (1965).

19. T. Kato, A. Takahashi, M. Nagasawa, and I. Kagawa, J. Chem. Soc. Jpn., 88, 524 (1967).

20. M. Kurata, H. Uchiyama and K. Kamada, Makromol. Chem., 88, 281 (1965).
21. T. Homma, K. Kawahara, H. Fujita, and M. Ueda, Makromol. Chem., 67, 132 (1963).

22. D. Vofsi and A. V. Tobolsky, J. Polym. Sci., Part $A, 3,3261$ (1965).

23. M. P. Dreyfuss and P. Dreyfuss, Polymer, 6, 93 (1965).

24. A. Miyake and W. H. Stockmayer, Makromol. Chem., 88, 90 (1965). 